\title{
Mortars Containing Sustainable PCM's for the Energy Efficiency of Buildings
}

\author{
Mariaenrica Frigione ${ }^{1, a}$, Mariateresa Lettieri ${ }^{2}$, Antonella Sarcinella ${ }^{1}$ and José Luis Barroso de Aguiar ${ }^{3}$ \\ ${ }^{1}$ Innovation Engineering Department, University of Salento, Italy \\ ${ }^{2}$ Institute of Archaeological Heritage, Monuments and Sites, CNR-IBAM, Italy \\ ${ }^{3}$ Civil Engineering Department, University of Minho, Portugal
}

\begin{abstract}
Energy use in buildings represents more than one-third of global energy consumption and contributes to nearly one-quarter of greenhouse gases emission worldwide. The thermal comfort demand represents one of the main cause of the increased energy consumption. To guarantee a thermal indoor comfort, contributing at the same time to the energy saving, the Thermal Energy Storage (TES) methodologies have recently gained interest. These technologies involve the use of a smart material, i.e. a Phase Change Material (PCM), with the capability to absorb/release energy from/in the environment; it can be easily integrated into a building material, such as a mortar. In this work, aerial lime-based mortar with the incorporation of an eco-sustainable PCM have been analyzed with the purpose to improve the energy efficiency of buildings. For its non-toxic nature, a thermoplastic polymer has been selected as PCM, i.e. Poly-Ethylene Glycol (PEG 1000). This material was included in an inert support obtained as byproduct of stone extraction from quarry. The final product, i.e. PEG/stone, can be regarded as a composite to be used as mortar aggregate. A preliminary (chemical and physical) characterization of this compound shown that the sustainable aggregates PEG/stone have an appropriate Latent Heat Thermal Energy Storage (LHTES). The addition of these aggregates into a mortar compositions lead to an unsuitable reduction of mechanical properties.
\end{abstract}

\section{Introduction}

Currently, the research is strongly oriented to find new and alternative methods to decrease the global energy consumption. The concern about climate change and about the rapid depletion of natural resources led the international policy to incentive the study aimed at evolving new renewable energy solutions [1].

Actually, the building sector is one of the largest consumers of energy and, according to the International Energy Agency (IEA) the main cause is connected to the higher demand for indoor thermal comfort. In these years, among all the proposed solutions and technologies, Thermal Energy Storage (TES) is considered the best approaches to improve the energy efficiency and to limit the energy consumption of buildings [2].

This technology involves a Phase Change Material $(\mathrm{PCM})$ as thermal storage medium. The operating principle of a PCM consists in changing its physical state, having a solid - liquid transition, according to the environment temperature. The PCM material melts, when the external temperature is higher, and store the enthalpy involved in this melting process. Then, when the external temperature decreases, it is able to release the previously stored energy, changing its status [3]. Adding a suitable PCM in construction materials can be a possible and an efficient solution to reduce energetic consumption.
In this work, the selected PCM was included into an inorganic porous matrix in order to produce a PCM composite system through the form stable method.

This composite system was produced employing as support small pieces of Lecce Stone (LS) available as a waste product, in order to maintain low the costs and to respect eco-sustainable principles; while, a low toxic, low flammable PEG (Poly-Ethylene Glycol) was selected as PCM. This material was chosen for its favorable properties, mostly because of its suitable phase change temperatures and large phase change enthalpy.

Furthermore, it is also characterized by an elevated long-term thermal/chemical stability, low toxicity and high resistance to corrosion [4]. The PCM form-stable systems was, then, used as aggregate in the production of aerial lime-based mortar formulations. The main aims of the research described in this paper were the production of a new sustainable PCM, i.e. LS/PEG composite, and its use as aggregate into the mortar compositions. First of all, a complete characterization of LS/PEG composite was performed, from a chemical, physical and thermal point of view. Then, the effects of the PCM presence on some properties of the aerial lime-based mortars, such as workability, compressive and flexural strengths, were analyzed.

\footnotetext{
${ }^{\mathrm{a}}$ Corresponding author: mariaenrica.frigione@unisalento.it
} 


\section{Materials and methods}

\subsection{Materials}

To produce the composite PCM, Lecce Stone (LS) was selected as support matrix because of its high open porosity and porosimetric features. This specific property make it suitable as support to prepare PCM composite system using the form-stable method, through the vacuum impregnation process. This method was selected due to its low manufacture costs. LS is a biocalcarenite, mostly used in historical buildings in the Southeastern Italy (Salento region). This material is mainly composed of $\mathrm{CaCO}_{3}(92-95 \%$ wt.) and other minerals in a smaller percentage [5]. The LS used in this work was a waste material supplied by a quarry located near Lecce (Italy), in form of flakes (Figure 1a). Then, it was ground by a mill and sieved to obtain small granules (Figure 1b), having a granulometry ranging between 1.6 and $2.0 \mathrm{~mm}$ [6]. Poly-Ethylene Glycol (PEG 1000) was selected as PCM because of its favorable properties, such as low toxicity, low environmental impact and low flammability [4]. It was supplied from Sigma - Aldrich company (Germany) in solid form (Figure 1c). The density of PEG 1000 , according to the technical data sheet, is $1.2 \mathrm{~g} / \mathrm{cm}^{3}$ (at $20^{\circ} \mathrm{C}$ ).

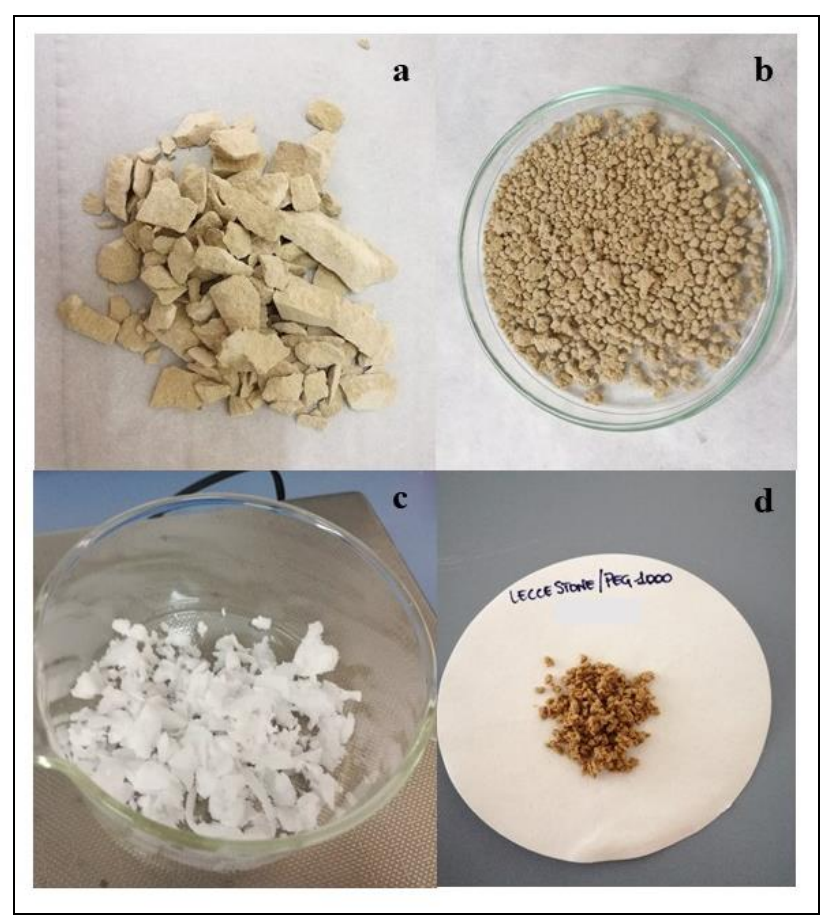

Figure 1. (a) Flakes of LS from the quarry; (b) ground and sieved Lecce Stone; (c) solid Poly-Ethylene Glycol (PEG); (d) LS/PEG composite system.

Briefly, the procedure to develop the LS/PEG composite system (Figure 1d) is described: a flask connected to a vacuum pump (at a vacuum pressure of $0.1 \mathrm{MPa}$ ) was used to contain a fixed amount of LS granules. Since PEG, at the environmental temperature, is solid, it was heated in oven at $80^{\circ} \mathrm{C}$, in order to lead it in the liquid state. Then, it was added to the LS granules in the flask, where a magnetic stir bar was also contained. The flask was placed on a magnetic stirrer, maintained at $60^{\circ} \mathrm{C}$, for $60 \mathrm{~min}$. At that point, air was allowed to enter in the flask to force the liquid PCM to penetrate into the pores of LS.

Mortars formulations were developed using aerial lime as binder, supplied by a Portuguese company (i.e., Lhoist). The aerial lime had a purity of $90 \%$ and a density of $2450 \mathrm{~kg} / \mathrm{m}^{3}$. A superplasticizer (SP) was added in order to decrease the amount of water to be used for the mixing. The employed superplasticizer was a polyacrylate (MasterGlenium SKY 627), supplied by BASF, with a density of $1050 \mathrm{~kg} / \mathrm{m}^{3}$. The compositions of the produced mortars, reported in Table 1, were realized according to the European Norm EN 998-1 [7].

Furthermore, for comparison purposes, similar formulations, including LS and LS/PEG as aggregates in the same composition, were prepared.

Table 1. Mortar formulations $\left(\mathrm{kg} / \mathrm{m}^{3}\right)$.

\begin{tabular}{|c|c|c|c|c|c|c|}
\hline System & $\begin{array}{c}\text { Binder } \\
\text { Aerial } \\
\text { lime) }\end{array}$ & $\begin{array}{c}\text { Aggre } \\
\text { gates }\end{array}$ & SP & $\begin{array}{c}\text { Wa } \\
\text { ter }\end{array}$ & $\begin{array}{c}\text { Water } \\
\text { satura }_{\text {tion }^{\mathbf{a}}}\end{array}$ & $\begin{array}{c}\text { Water/ } \\
\text { Binder }\end{array}$ \\
\hline AL_LS & 500 & 1500 & 0 & 289 & 378 & 0.60 \\
\hline $\begin{array}{c}\text { AL_LS/ } \\
\text { PEG }\end{array}$ & 500 & 1500 & 0 & 395 & 0 & 0.80 \\
\hline $\begin{array}{c}\text { AL_LS } \\
\text { SP }\end{array}$ & 500 & 1232 & 15 & 225 & 414 & 0.45 \\
\hline
\end{tabular}

${ }^{\mathrm{a}}$ This parameter represents the water used to saturate the LS aggregates to prevent them from absorbing water needed in the manufacture of mortars. In the case of LS/PEG composite, the saturation step was not required since PEG already saturated the pores of LS.

\subsection{Methods}

To analyzed the morphology and microstructure of both the pure LS and the form-stable LS/PEG was used a Scanning Electronic Microscope (SEM, Carl Zeiss Auriga40 Crossbeam instrument), with an acceleration voltage of $2-5 \mathrm{kV}$.

A Fourier Transform Infrared Spectroscopy (FT-IR, ThermoNicolet Nexus spectrometer), was used for the chemical characterization of the LS/PEG systems. The samples were mixed with $\mathrm{KBr}$ pellets and analyzed in transmission mode. The spectra were acquired in the range of 4000-400 $\mathrm{cm}^{-1}$, with a resolution of $4 \mathrm{~cm}^{-1}$ and 32 scans per measurement.

The thermal properties of both the pure PEG and the produced LS/PEG systems were measured with a Differential Scanning Calorimetry (DSC, Stare System, Mettler Toledo) instrument. The sample was subjected to sequential thermal cycles, between $-10^{\circ}$ to $100^{\circ} \mathrm{C}$ on heating, and from $100^{\circ}$ to $-10^{\circ} \mathrm{C}$ on cooling with a rates of $10^{\circ} \mathrm{C} / \mathrm{min}$; the tests were performed under nitrogen atmosphere. Three samples were analyzed and the results averaged. The thermal degradation process of pure PEG and the LS/PEG system was studied through a TGA/DSC1 (Stare System) instrument, produced by Mettler Toledo. Thermo-gravimetric analysis (TGA) were conducted at a heating rate of $10^{\circ} \mathrm{C} / \mathrm{min}$, in the 
range $25^{\circ}-450^{\circ} \mathrm{C}$, once again under nitrogen atmosphere. The test was repeated three times for each system.

The workability of the different mortars produced, reported in Table 1, in fresh state was evaluated through the flow table method, according to the European standard EN 1015-3 [8]. The mechanical characteristics, in flexural and compressive mode, of the produced mortars were determined according to the European standard EN 1015-11 [9] using a Lloyd dynamometer instrument. For each mortar composition, 3 prismatic specimens $\left(40 \times 40 \times 160 \mathrm{~mm}^{3}\right)$ were prepared by casting the fresh mortars in iron molds. The specimens were seasoned for 28 days at standard temperature $\left(25^{\circ} \mathrm{C}\right)$ and humidity $(50 \%)$. The flexural tests were, then, performed at a speed of $6 \mu \mathrm{m} / \mathrm{s}$, while the compressive tests at a speed of $12 \mu \mathrm{m} / \mathrm{s}$.

\section{Results and discussion}

SEM observations were used to examine the impregnation of the LS granules. In Figure 2 the SEM images of the untreated and treated granules of LS are compared. The surface of the pure LS appeared rough, with evident small cavities due to the pore structure (Figure 2a). After the impregnation, the surface appeared smoother because of the presence of PEG and the impregnation seemed uniform (Figure 2b).
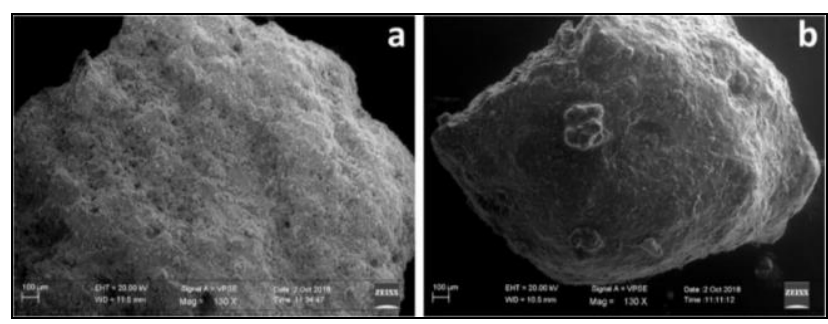

Figure 2. SEM images of untreated and treated stone granules: (a) LS, (b) LS/PEG.

To investigate the chemical compatibility and the possible interactions between PEG and LS, the neat materials and the PCM composites were characterized by FT-IR. The acquired spectra are reported in Figure 3.

The FT-IR spectrum of the stone revealed the presence of calcite $\left(1797,1420,872\right.$ and $\left.713 \mathrm{~cm}^{-1}\right)$ and low amounts of silicate minerals $\left(1035 \mathrm{~cm}^{-1}\right)$. In the spectra of the LS/PEG composite material, no new signal was observed other than the typical bands of PEG and LS. This proved that no chemical interaction occurred between PEG and the stone material. Nevertheless, slight shifts (i.e., the peak at $1114 \mathrm{~cm}^{-1}$ shifted to $1104 \mathrm{~cm}^{-1}$ ), observed in the spectra of the composites, indicate some physical attractions, including hydrogen bonds [10], between the two components. This physical interaction can contribute to the stability of the PCM material because the PEG molecules are tied to the stone and lose their freedom of motion.

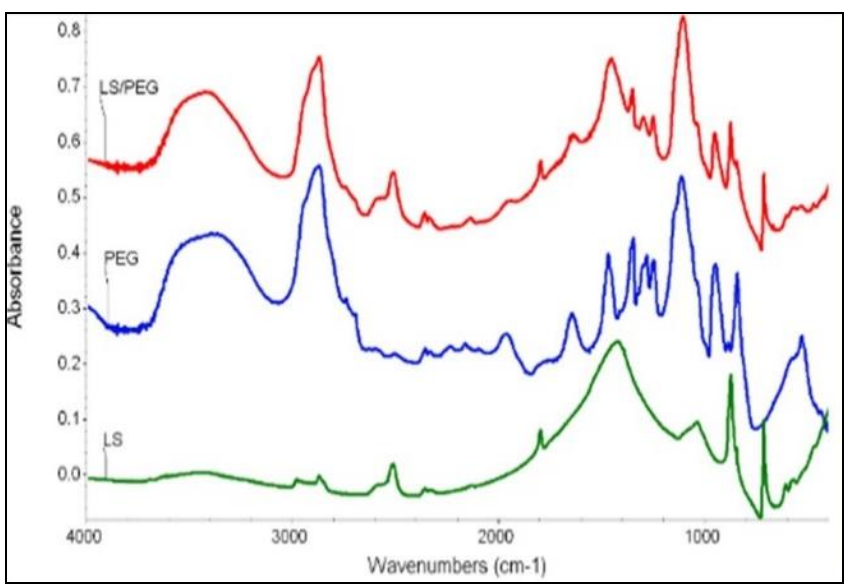

Figure 3. FT-IR spectra of pure components, LS and PEG and LS/PEG composites.

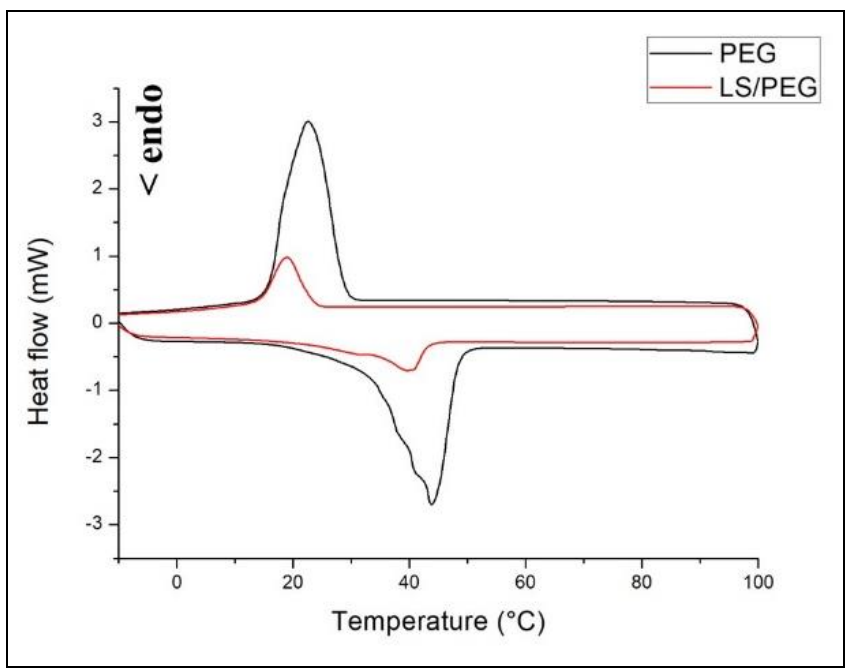

Figure 4. DSC curves of the pure PEG and of LS/PEG composite.

The measurement of the melting temperature and LHTES capacity is an important aspect to evaluate the thermal properties of PCM-stone composites. Figure 4 shows the DSC thermograms of pure PEG and of LS/PEG, including both heating and cooling cycles. The characteristic temperatures and the related latent heat capacities are summarized in Table 2.

Table 2. Characteristic temperatures and LHTES properties of PEG and LS/PEG composites.

\begin{tabular}{|c|c|c|c|c|}
\cline { 2 - 5 } \multicolumn{1}{c|}{} & \multicolumn{2}{c|}{ Heating } & \multicolumn{2}{c|}{ Cooling } \\
\hline System & $\mathbf{T m}\left({ }^{\circ} \mathbf{C}\right)$ & $\Delta \mathbf{H m}(\mathbf{J} / \mathbf{g})$ & $\mathbf{T c}\left({ }^{\circ} \mathbf{C}\right)$ & $\Delta \mathbf{H c}(\mathbf{J} / \mathbf{g})$ \\
\hline PEG & $42.8 \pm$ & $129.3 \pm$ & $23.6 \pm$ & $129.8 \pm$ \\
1000 & 1.1 & 1.2 & 1.2 & 0.8 \\
\hline \multirow{2}{*}{ LS/PEG } & $39.3 \pm$ & $27.7 \pm$ & $19.4 \pm$ & $26.2 \pm$ \\
& 0.7 & 0.9 & 0.9 & 1.1 \\
\hline
\end{tabular}

As reported in Table 2 and shown in Figure 4, the DSC curve observed for LS/PEG composites in both the melting and crystallization processes are shifted toward lower temperatures, probably due to surface interactions between PEG and the LS porous substrate [11]. In addition, as expected, differences between the melting 
and crystallization enthalpies of PEG and of PEG-stone composites was measured. This difference is related to the lower amount of PEG into the LS/PEG composite samples. For TES applications, the thermal resistance and the thermal stability are important properties for a PCM.

TGA was used to evaluate these parameters. The obtained results are briefly summarized in Table 3 and shown in Figure 5. Here it is possible to observe that PEG begins to lose weight at $220^{\circ} \mathrm{C}$, and the degradation process is complete just above $400^{\circ} \mathrm{C}$. For this reason, the selected PCM can be regarded as a material with high thermal resistance and good thermal stability, as reported in literature $[4,12]$. On the other hand, the complete degradation of PEG incorporated into the LS granules occurs at a lower temperature, i.e., at around $290^{\circ} \mathrm{C}$. This result could be ascribed to the low amount of PEG. Still, the produced PCM composites display a suitable thermal resistance and thermal stability for the intended purposes [10]. TGA analysis was also employed to evaluate the amount of PEG truly absorbed by the granules of LS. The percentage of PEG contained was estimated around $20 \%$ by weight.

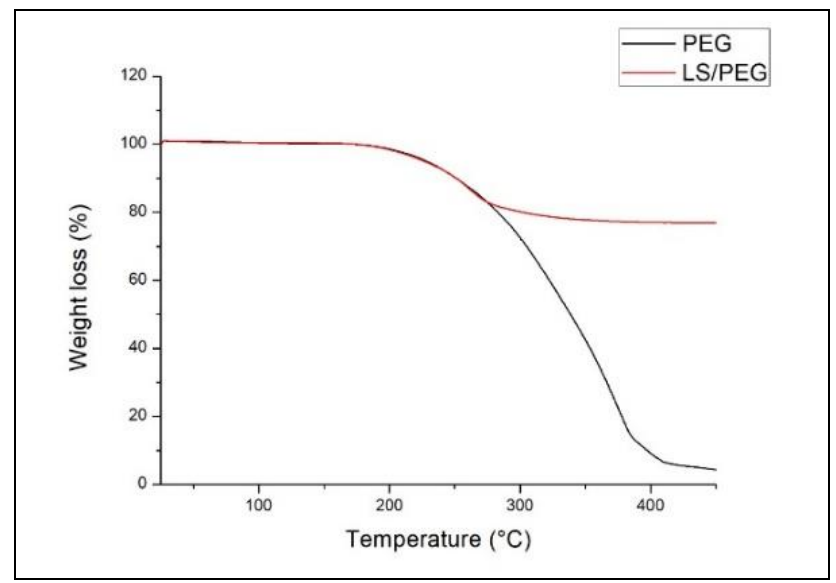

Figure 5. TGA curves of the pure PEG and PCM-stone composites.

Table 3. Degradation temperatures and percentage composition of PEG and LS/PEG composite.

\begin{tabular}{|c|c|c|c|c|}
\hline System & $\begin{array}{c}\text { Onset } \\
\left({ }^{\circ} \mathbf{C}\right)\end{array}$ & $\begin{array}{c}\text { Endset } \\
\left({ }^{\circ} \mathbf{C}\right)\end{array}$ & $\begin{array}{c}\text { Residual } \\
\text { mass (\%) }\end{array}$ & $\begin{array}{c}\text { Amount of } \\
\text { PEG (\%) }\end{array}$ \\
\hline PEG & 220.2 & $401.1 \pm$ & $1.7 \pm 0.5$ & $98.3 \pm 0.5$ \\
1000 & \pm 1.2 & 1.1 & \pm & \pm .1 \\
\hline LS/PEG & $\begin{array}{c}219.1 \\
\pm 1.2\end{array}$ & $\begin{array}{c}292.6 \pm \\
1.2\end{array}$ & $77.0 \pm 1.0$ & $23.0 \pm 1.4$ \\
\hline
\end{tabular}

After the characterization of PEG and LS/PEG aggregates, the study was focused on the development of aerial lime-based mortars. The workability test on the produced aerial lime-based mortars was first performed.

For this work, the appropriate value of workability was chosen in the range of 160-180 $\mathrm{mm}$. Then, according to the European standard EN 1015-11, flexural and compressive tests were carried out. In Table 4 the workability values for the developed mortars and the mechanical properties are reported.
Table 4. Values of workability and mechanical properties measured in flexural and compressive mode.

\begin{tabular}{|c|c|c|c|}
\hline System & $\begin{array}{c}\text { Workability } \\
(\mathbf{m m})\end{array}$ & $\begin{array}{c}\text { Flexural } \\
\text { strength } \\
(\mathbf{M P a})\end{array}$ & $\begin{array}{c}\text { Compressive } \\
\text { strength (MPa) }\end{array}$ \\
\hline AL_LS & 161 & $\begin{array}{c}0.51 \pm \\
0.10\end{array}$ & $\begin{array}{c}0.52 \pm 0.04 \\
\text { CSI }^{\mathrm{a}}\end{array}$ \\
\hline AL_LS/PEG & 170 & $\begin{array}{c}0.20 \pm \\
0.07\end{array}$ & $\begin{array}{c}0.24 \pm 0.05 \\
\text { n.a. }\end{array}$ \\
\hline AL_LS_SP & 173 & $\begin{array}{c}\mathrm{b} \\
0.64 \pm\end{array}$ & $\begin{array}{c}0.69 \pm 0.09 \\
\text { CSI }^{\mathrm{a}}\end{array}$ \\
\hline
\end{tabular}

${ }^{a}$ Category of the mechanical resistance of the mortar according to the standard NP EN 998-1.

${ }^{\mathrm{b}}$ Not applicable.

To assure a good workability to a mortar formulation a proper content of water is necessary. Nevertheless, this amount should not be excessive because it might lead to a high porosity in the mortar and, as a consequence, to unsuitable mechanical properties [13]. For this reason, superplasticizers are widespread used due to their capability to improve the workability of the mortars using limited amounts of water. As reported in Table 4, it was possible to obtain an appropriate value of workability for all the formulations analyzed. According to the results presented in Table 4, a decrease in the flexural and compressive strengths of aerial lime-based mortars is observed because of the introduction of the LS/PEG composite. The presence of these aggregates lead to a greater content of water requested by $\mathrm{AL} \_\mathrm{LS} / \mathrm{PEG}$ composition. On the other hand, the use of a superplasticizer in the sample mortar AL_LS_SP, containing LS as aggregate, allowed to obtained increased values for both flexural and compressive strengths. Taking into account the intended application of the produced mortars in the field of constructions, it must be underlined that they should have a minimum classification of CS II based on the compressive strength.

The mortars produced in this study, possess mechanical characteristics not completely adequate (CS I type), even adding the superplasticizer.

\section{Conclusions}

In this paper, the production of a composite PCM, to be included in mortars as aggregates, is described. The used form-stable method, has proved to be successful in effectively impregnating the granules of stone with the selected PCM, leading to the production of a new and sustainable PCM composite, LS/PEG. This latter was characterized through, SEM, FT-IR, DSC and TGA analysis. SEM observations were used to investigate the surface of the LS granules and it was found that the LS granules was uniformly covered by PEG. A deeper analysis was carried out through the FT-IR spectroscopy and the results shown that no chemical interaction occurred between PEG and the stone material. However, some signals observed in the spectra of the composites system, indicated some physical attractions, between the two components, which could contribute to the stability of the PCM material. LHTES properties and thermal 
resistance characteristics of the LS/PEG composites, investigated by DSC and TGA, respectively, shown appropriate thermal properties (i.e., suitable phase change temperatures and large phase change enthalpy) and good thermal stability. In conclusion, the measured properties confirm that these materials can be regarded as promising candidates for building applications. Therefore, the composite system LS/PEG was introduced as aggregates to the aerial lime-based mortar composition. The incorporation of these composite aggregates led to a decrease of flexural and compressive strength values, because the mortar composition containing the LS/PEG aggregates require a large amount of water. This lead, as consequence, to a higher porosity of the mortar that has a negative effect on the mechanical properties. In order to achieve an adequate workability of the fresh mixtures and, the same time, to maintain low the addition of water, it was necessary to employ a superplasticizer. In this way was possible to achieve a slight increase in the mechanical performance but still not adequate to the intended purpose of this research. Starting from these results, the future research is focused on the development of new mortar compositions based on different binders with the aim to achieve adequate mechanical properties.

Then, the study of their thermal behavior will be the next step.

\section{References}

1. M. Song, F. Niu, N. Mao, Y. Hu, and S. Deng, Energy and Buildings 158, 776 (2018)

2. M. Frigione, M. Lettieri, and A. Sarcinella, Materials 12, (2019)
3. V. V. Rao, R. Parameshwaran, and V. V. Ram, Energy and Buildings 158, 95 (2018)

4. Y. Kou, S. Wang, J. Luo, K. Sun, J. Zhang, Z. Tan, and Q. Shi, The Journal of Chemical Thermodynamics 128, 259 (2019)

5. G. F. Andriani and N. Walsh, Geological Society, London, Special Publications 333, 129 (2010)

6. M. Frigione, M. Lettieri, A. Sarcinella, and J. B. de Aguiar, in International Congress on Polymers in Concrete (ICPIC 2018), edited by M. M. R. Taha (Springer International Publishing, Cham, 2018), pp. 195-201

7. EN 998-1: 2010: Specification for Mortar for Masonry - Part 1: Rendering and Plastering Mortar. CEN: Brussels 2010.

8. European Committee for Standardization (CEN), EN 1015-3 (2004), Methods of Test for Mortar for Mansonry - Part 3: Determination of Consistence of Fresh Mortar (by Flow Table).

9. European Committee for Standardization (CEN), EN 1015-11 (1999), Methods of Test for Mortar for Masonry - Part 11: Determination of Flexural and Compressive Strength of Hardened Mortar.

10. A. Sar1, Energy Conversion and Management 117, 132 (2016)

11. Y. Deng, M. He, J. Li, and Z. Yang, Polymers 10, 889 (2018)

12. S. Karaman, A. Karaipekli, A. Sarı, and A. Biçer, Solar Energy Materials and Solar Cells 95, 1647 (2011)

13. S. Cunha, J. B. Aguiar, V. Ferreira, and A. Tadeu, Advanced Materials Research 687, 255 (2013) 